\title{
"It does not Mean that They Cannot Do Mathematics": Beliefs about Mathematics Learning Difficulties
}

\author{
Shemunyenge Taleiko Hamukwaya $\left.{ }^{1 *} \mathbb{(}\right)$, Çiğgdem Haser ${ }^{2^{* *}}$ (1)
}

\author{
${ }^{1}$ Department of Mathematics and Statistics, University of Turku, Turku, FINLAND \\ ${ }^{2}$ Department of Teacher Education, University of Turku, Rauma, FINLAND \\ ${ }^{\star}$ Corresponding Author: shtaha@utu.fi \\ ${ }^{\star \star}$ Corresponding Author: cigdem.haser@utu.fi
}

Citation: Hamukwaya, S. T., \& Haser, Ç. (2021). "It does not Mean that They Cannot Do Mathematics": Beliefs about Mathematics Learning Difficulties. International Electronic Journal of Mathematics Education, 16(1), em0622. https://doi.org/10.29333/iejme/9569

ARTICLE INFO

Received: 18 Jul. 2020

Accepted: 22 Oct. 2020

\begin{abstract}
Namibian preservice high school mathematics teachers' $(\mathrm{N}=4)$ and teacher educators' $(\mathrm{N}=3)$ beliefs about mathematics learning difficulties (MLD) were investigated to document the beliefs developed at the end of the teacher education program, the views and practices that might be emphasized in the program, and possible changes in these beliefs during the first year teaching. Preservice teachers were interviewed before they graduated from the teacher education program and during their first-year teaching. Teacher educators were interviewed once. Participants believed that the most important factor causing MLD at the high school was students' knowledge and beliefs. Teacher educators stated former unqualified teachers and preservice teachers stated curriculum and teachers' workload as other causes of MLD. Participants suggested individual support and mixed ability grouping to reduce students' MLD. The partial alignment of beliefs among the participants showed that preservice teachers might have developed some beliefs through the views and practices emphasized in the program. Preservice teachers elaborated more on MLD when they became teachers and stated similar beliefs with some stress on their MLD-related practices. Preservice teachers did not comment on how teachers' knowledge and practices might influence students' MLD in both times. Findings pointed that teacher education programs should focus on increasing preservice teachers' awareness of how their knowledge, practices and beliefs about MLD might affect students to improve their future practices. It is possible that teachers' beliefs about MLD could be related to their beliefs about the nature of mathematical knowledge and indicators of high performance in mathematics.
\end{abstract}

Keywords: mathematics learning difficulties, Namibia, teachers' beliefs

\section{INTRODUCTION}

Investigating beliefs has been an important line of research in the field of education (Fives \& Buehl, 2012) and mathematics education (Cross Francis, Rapacki, \& Eker, 2015; Philipp, 2007; Thompson, 1992). There are several, mostly similar, yet not agreed upon definitions for the term "beliefs" in the field of education (Pajares, 1992) and the field of mathematics education (Cross Francis et al., 2015; Furinghetti \& Pehkonen, 2002; Goldin, Rösken, \& Törner, 2009). Yet, it can be stated that in the most general sense, and in this study, teachers' beliefs are considered as the understandings that they take as true about the world (Philipp, 2007) mostly developed through their experiences and interactions with the others, and observations especially in the case of preservice teachers (Pajares, 1992). These understandings, which are shaped by teachers' experiences in dealing with mathematics (Raymond, 1997), influence their decisions about what they plan for their practice and how they enact this plan in the mathematics classrooms (Cross Francis et al., 2015). Teachers' beliefs in the field of mathematics education have been widely investigated in terms of their beliefs about the nature of the mathematical knowledge, teaching mathematics and learning mathematics in general (Philipp, 2007; Thompson, 1992), which are referred as the mathematics related beliefs in the present study. These studies have provided insights into the nature of teachers' beliefs and the nature of the relationship between their beliefs and practices. The present study contributes to this line of research through: (i) investigating beliefs in the context of Namibia where mathematics related beliefs have not been investigated much; and (ii) exploring beliefs about mathematics learning difficulties (MLD) where research studies are rather scarce. As we did not have the opportunity to observe participants' teaching practices, the present study did not focus on the relationship between mathematics teachers' beliefs about MLD and their practices.

Teachers' beliefs affect how they learn to teach in the teacher education programs and later how they improve themselves in their profession (Pajares, 1992). Their beliefs were developed mostly before they started to study in the teacher education 
programs, might change to some extent during their studies, and have the potential to influence their learning in the programs (Richardson, 2003). An example would be preservice teachers' beliefs about MLD, which might have been developed over the years (Scherer, Beswick, DeBlois, Healy, \& Opitz, 2016) by observing other students with MLD as a student, experiencing certain difficulties in mathematics, in their interactions with teacher educators in teacher education programs, and observing classrooms as soon-to-be-teachers. These beliefs have the potential to influence how preservice teachers address MLD when they become teachers and how they improve their practice to improve the learning of students with MLD.

Although explored rather less, research have found that teacher educators' beliefs influence their practices in the teacher education programs (Donche \& Van Petegem, 2011; Warren, 2019). Their beliefs have been investigated to address what they prioritize in their profession (e.g., Maaranen, Kynäslahti, Byman, Jyrhämä, \& Sintonen, 2019), and to what extent these beliefs affect their practices and students (e.g., Donche \& Van Petegem, 2011). A rare study in the field of mathematics education found that preservice teachers' mathematics related beliefs were more similar to those of teacher educators at the end of their studies, which indicated that teacher educators' beliefs could be reflected in the teacher education programs and in preservice teachers' beliefs to some extent (Felbrich, Müller, \& Blömeke, 2008).

Research studies on the mathematics related beliefs and their relationship to teachers' practices also have explored how teachers hold these beliefs, employing Green's (1971) belief system metaphor to a great extent (Gomez \& Conner, 2020). Belief system metaphor has provided an essential guide for exploring teachers' mathematics related beliefs (Beswick, 2018) and provided the field with a tool to understand how one comes to believe what one believes, how one's beliefs are related to other beliefs and how they influence one's action (Haser \& Doğan, 2012). Green addressed beliefs in a system of isolated clusters of related beliefs. The isolated clusters make it possible for individuals to hold contradictory beliefs (Green, 1971). Green explains the character of belief systems as follows: (1) there are primary beliefs and derivative beliefs of these primary beliefs in the system, suggesting a quasi-logical relationship; (2) some beliefs are stronger (resist more to change) than others and more central in the belief system, whereas as others are less strong and more peripheral; and (3) individuals hold some beliefs evidentially (based on evidence or reason, and possibly experience) and some others non-evidentially. Belief system metaphor was employed in this study to provide a possible explanation for how participants' beliefs about MLD might be held in participants' belief systems in relation to the other mathematics related beliefs so that further studies could focus on the possible connections among such beliefs.

Numerous studies have documented preservice teachers' mathematics related beliefs and specific belief systems at the end of their studies before they start to teach in schools, with or without any specific intervention. The present study documents Namibian preservice secondary mathematics teachers' beliefs about MLD both at the end of the teacher education program and in their first-year teaching without any intervention. It also addresses the beliefs of a rather underrepresented group in the field of mathematics education, the teacher educators, and provides an insight about the views and practices that might be emphasized in the teacher education programs. It cautiously provides a possible proposal about how preservice teachers' beliefs about MLD might be placed in their belief systems.

It is important to clarify our choice of the term "mathematics learning difficulties." Our interest is not on beliefs about mathematics learning disabilities, which are "biologically driven disabilities specific to mathematics" (Mazzocco, 2009, p. 1). We are rather interested in "mathematics learning difficulties", which addresses an array of difficulties in mathematics that students have because of one or a combination of several reasons, such as biological differences, limited opportunities due to socioeconomic status, limited access to proper early support, mathematics content, lack of adequate prior knowledge, teaching practices (Chinn, 2015), and ineffective instruction and materials (Carnine, Jitendra, \& Silbert, 1997). In addition, home environment (Reusser, 2000), cultural differences and parents' beliefs about learning and/or lack of interest in children's learning (Jordan \& Levine, 2009) have influence on MLD.

In their review of the studies about effective practices for MLD, Scherer, Beswick, DeBlois, Healy, and Opitz (2016) consider students with MLD as the ones who do not perform as expected and need meticulous support in their learning of mathematics. The studies they review have addressed that students with MLD have both procedural (such as counting and remembering of some basic facts) and conceptual (such as difficulties in understanding the place value system, grouping and counting principles, and understanding and expressing word problems in mathematical statements) difficulties. MLD in the present study refer to the difficulties that students experience in mathematics concepts and procedures as indicated by continuous low achievement or low performance in mathematics (Beswick, 2007/2008; Mazzocco, 2009) and a slow pace in growth of mathematical knowledge and skills compared to the expected growth (Morgan, Farkas, \& Wu, 2009), which might be due to several reasons stated above (Carnine et al., 1997; Chinn, 2015: Jordan \& Levine, 2009; Reusser, 2000) as observable by teachers, but not necessarily to only a disability. Therefore, students with or without any disabilities might have MLD, while the former have it due to neurodevelopmental factors, the latter have it due to a combination of several contextual factors as described above. In the present study, we do not specifically consider all low achievers as students with MLD, nor do we stress clear distinctions between students with mathematical disabilities (as identifiable by biological traits) and students with MLD. Instead, we address that students with certain characteristics, such as continuous low performance and slow progress in understanding both procedural and conceptual mathematical knowledge compared to the expected performance and progress in school mathematics, who need carefully planned support to improve their mathematical performance, are the students with MLD. While not all low achievers are students with MLD and they simply might be not studying effectively or being assessed adequately, low achievement in mathematics is one of the indicators for MLD. Students with MLD could be seen in regular or inclusive classrooms and may be attended by the class teachers, mathematics teachers, and special education teachers. Whether they have disabilities or not could be determined with competent specialists in this field. Regardless of the source of the MLD, these students are mostly in classrooms with students who progress in their studies as expected, and are observed and taught by mathematics teachers. 
As we do not work in the field of special education or disabilities, we built our study and arguments on the studies about teachers' and specifically mathematics teachers' beliefs about MLD and low achievement in mathematics. We did not explicitly point or exclude disabilities in the interviews for the participants to allow them express their beliefs without any restriction. "Beliefs about MLD" in this study include beliefs about the students with MLD, the possible reasons for the MLD, and the possible ways to deal with it.

\section{TEACHERS' BELIEFS ABOUT MATHEMATICS LEARNING DIFFICULTIES}

There is a wide range of studies about teachers' views on inclusion and learning disabilities in mathematics, and effective interventions. Although we intentionally do not focus on this literature, it is important to note that the rationale behind these studies was that teachers' (and in some cases mathematics teachers') beliefs about inclusion of students with mathematics learning disabilities had a considerable effect in their classroom practices and implementing policies addressing these students (DeSimone \& Parmar, 2006a, 2006b).

The studies on teachers' beliefs about MLD, however, are quite scarce. The review of Scherer et al. (2016) of the limited number of studies shows that teachers' beliefs about MLD and special education contexts in mathematics have influence on the strategies they use in the classrooms and their thinking about students' aptitudes. Although there are not many studies on teachers' beliefs about MLD, teachers do observe their students and try to identify their difficulties in order to support their students' mathematics learning (Van Steenbrugge, Valcke, \& Desoete, 2010). It is possible that these observations lead teachers to certain beliefs about MLD and how students should be supported in their mathematics learning.

Beswick (2007/2008) asked Australian elementary and middle school mathematics teachers to identify the students' difficulties in mathematics and what they prioritized for teaching students with MLD in a professional development program. They stated that students had difficulties in several concepts and highlighted several issues to deal with MLD such as using concrete materials for reasoning, developing metacognition, and enhancing students' verbal expression of their thinking. Then, they worked on numeracy tasks, materials and activities to improve students' understanding. The questionnaire that Beswick implemented in the beginning and at the end of the program showed that many teachers linked MLD to factors other than teaching even at the end of the program. Although more teachers addressed conceptual understanding as a goal for students with MLD, they still believed that it was more suitable for students without MLD. Yet, these beliefs were changed to some extent when teachers were trained to develop materials and strategies for MLD, which suggested that they might be held evidentially in teachers' belief systems (Beswick, 2007/2008).

In another study, Beswick (2017) asked Australian secondary mathematics teachers about the characteristics of their "poor" and "good" students, and how these characteristics were reflected in their pedagogical choices in professional development program. Teachers characterized poor students of mathematics with poor computational skills, lack of sufficient understanding of prior concepts, slowness in completing tasks, and failure to develop mental strategies. These students had negative attitudes, low self-efficacy, lack of interest and effort, and lack of desire to deal with difficult tasks. They did not attend or participate in lessons, pay attention, ask for help or concentrate, and they disrupted others. Teachers believed that these students should be given tasks within their interest level that they could answer correctly. They suggested one-on-one help, same-ability group work and special programs for these students to improve their mathematics learning. Good students, on the hand, were not characterized with what poor students did not have, such as good computational skills. They had higher level mathematical proficiency indicators, such as problem solving skills and tendency to deal with challenging tasks. Beswick claimed that teachers might believe that poor students were successful when they improved basic computational skills, although they did not explicitly state this in the study. Beswick (2007/2008, 2017)'s studies showed that teachers might have lower expectations for students with MLD or believe that those students might be given less difficult and less challenging tasks. Teachers of the other subjects also believe that higher thinking skills might not be proper for low achieving students, because tasks with higher thinking skills are beyond these students' capabilities and they will only discourage them (Zohar, Degani, \& Vaaknin, 2001). It might be the case that teachers tend to have such beliefs regardless of what they teach.

Studies conducted in a more general sense might provide a wider perspective about teachers' beliefs about learning difficulties, and how these beliefs might affect their decisions and practices in the classrooms. Soodak and Podell (1994) explored teachers' beliefs about difficult-to-teach students and how to address their difficulties. They presented elementary teachers the case of a student with family problems, disruptive behaviours, and difficulties in reading, and asked them what might be the reason for the student's difficulties and what they would do. Most of the teachers attributed the student's learning difficulties more to out-of-school factors, such as family or students' possible cognitive and emotional traits, than to school-related factors. These teachers also suggested interventions by outside parties, such as parents. Teachers who connected the difficulties to school-related factors suggested more teaching and learning alternatives for the student. While the findings of this study were limited by the case that was presented to the teachers, it also showed that teachers might prioritize out-of-school factors as reasons for students' difficulties and might not consider revising their teaching practices (Soodak \& Podell, 1994). In a similar way, especially experienced teachers tended to relate differences in students' achievement more to biological and rather stable factors, such as gender (favouring males), cognitive ability and family background, whereas preservice teachers tended to see it more as a result of teaching (Georgiou, 2008). Experienced teachers' beliefs might change over the years because they might realize that they were not solely responsible for students' achievement and not able to control other variables (Georgiou, 2008), and/or they might feel rather exhausted through the years and be looking for external support to address these students (Soodak \& Podell, 1994). Yet, these beliefs are likely to guide the teachers towards not adopting more differentiated approaches that would help students with learning difficulties (Soodak \& Podell, 1994). 
The broader context of the present study is Namibia, a country with a relatively young educational system going through certain challenges since gaining its independence in 1990 (Ministry of Education, Arts and Culture, 2017). The international comparison studies of African countries conducted by Southern and Eastern Africa Consortium for Monitoring Educational Quality (SACMEQ) revealed that sixth grade Namibian students' mathematics achievement was among the lowest in the first three SACMEQ studies conducted in 1995, 2000, and 2006 (SACMEQ, 2011); and increased to some extent in the last study in 2014 (Ministry of Education, Arts and Culture, 2017). Nambira, Kapenda, Tjipueja, and Sichombe (2009) have explored Namibian teachers' perceptions of the reasons for sixth, seventh and eighth grade students' low mathematics performance. Their findings indicated that teachers considered lack of motivation at home and school, perception of mathematics as a difficult topic, and the use of English as the medium of instruction as the reasons for students' low performance. Teachers addressed that students' lack of knowledge of previous topics made it difficult for them to learn the new related topics (Nambira, Kapenda, Tjipueja, \& Sichombe, 2009). Maemeko, Nkengbeza, and Ntabi (2017) explored Namibian teachers' perceptions of the reasons for $12^{\text {th }}$ grade students' general poor academic performance. Teachers expressed system-, school- and student-related factors as reasons and stated that students were admitted to high schools with inadequate knowledge and skills mostly taught and assessed by unqualified teachers, resulting in low achievement at the high school. Maemeko et al. found that teachers addressed the lack of resources in schools, adequate school infrastructure, and discipline at schools as other reasons. Teachers claimed that students were unmotivated and their poor home learning environment and inattentive parents did not support their studies.

When mathematics teachers start to teach in schools, they face many challenges which they have not realized or paid attention before (Flores \& Day, 2006). When they meet students with diverse prerequisite mathematics knowledge, who are supposed to be taught through one curriculum in their first year, their beliefs and/or practices tend to change (Haser \& Star, 2009). This change in mathematics related beliefs, however, is in the opposite direction of what the teacher education programs initiate and it is generally rapid (Flores \& Day, 2006; Raymond, 1997). Responding to the varied needs of students is likely to be difficult for beginning teachers when some of their students do not only lack certain knowledge or skills that could be effectively restored, but have MLD that require a more thoroughly planned instruction. Under such circumstances, it is possible that beginning teachers' beliefs about MLD, which would help them in providing effective teaching support for students with MLD, might change to the beliefs that would lead them towards looking for out-of-school interventions but not towards planning their teaching to address these students.

The studies stated above showed that teachers face an important challenge of how to make sense of MLD and how to enhance students' mathematical proficiency, where their decisions are affected by their beliefs (Scherer et al., 2016). They addressed that teachers' beliefs about MLD could be the key for the effective implementation of certain policies attending the learning needs of students with MLD (Beswick, 2007/2008). Therefore, teachers' beliefs about MLD should be taken into consideration to provide effective mathematics learning experiences for students. The limited number of studies about teachers' beliefs about MLD have focused on inservice teachers at different levels. Preservice and beginning mathematics teachers' beliefs about MLD have not been explored much.

The present study first focussed on Namibian preservice secondary mathematics teachers' and teacher educators' beliefs about MLD. It aimed to contribute to the mathematics education field, especially in the African context, by exploring preservice teachers' beliefs about MLD, and the alignment of their beliefs with the views and practices that might be emphasized in the teacher education program by exploring teacher educators' beliefs about MLD. Understanding beginning teachers' beliefs about MLD before they start to teach and monitoring their beliefs and practices in their first years are crucial for supporting them in their efforts to address all students in the classroom. Therefore, the study focused also on if preservice teachers' beliefs were changed when they started teaching in order to identify the issues that they might need support in relation to MLD. Our research questions were: (1) what are preservice secondary mathematics teachers' and teacher educators' beliefs about MLD at the high school level?; and (2) to what extent preservice high school mathematics teachers' beliefs about MLD change in their first year in teaching? While we did not specifically focus on teachers' belief systems in our study, we cautiously state that the study also had a rather implicit aim of providing an initial view of how teachers' beliefs about MLD might be related to other beliefs within their belief systems.

The focus on MLD at the high school level reflects the first author's (hereafter the researcher) experiences. The researcher had worked as a mathematics teacher at different levels of Namibian schools for 15 years. She observed that several students had MLD at the $11^{\text {th }}$ grade which made it difficult for them to pursue mathematics-related professions. The present study focused on this issue by exploring preservice teachers' and teacher educators' beliefs about MLD to provide a research-based knowledge for improving teacher education programs and professional development programs.

\section{METHODS}

The study was conducted as a basic qualitative research and it explored participants' interpretations of their experiences, the world they built around them and the meaning of these experiences for them (Merriam, 2009). Four preservice high school mathematics teachers and three teacher educators from the same Namibian teacher education program participated. The study was completed in two parts. Part I was conducted in 2018 with preservice teachers and teacher educators, and it aimed to address their beliefs based on their experiences and observations related to MLD. Part II was conducted with the preservice teachers of Part I when they became teachers in 2019. The focus was on their beliefs through exploring their observations and practices of teaching mathematics to the students with MLD. 


\section{Context}

\section{Namibian secondary education}

Namibia is a country of three million population. Pre-university education is structured with a national curriculum as primary (grades pre-primary-3, ages 6-9), senior primary (grades 4-7, ages 10-13), junior secondary (grades 8-10, ages 14-16), and senior secondary/high school (grades 11-12, ages 17-18) education. Students learn the school subjects in their mother tongue until grade 3 and in English afterwards. Namibian high school curriculum offers students to study at least six subjects of their choice including compulsory English and mathematics. The curriculum also provides opportunity for the students in grade 11 to select a field of study consisting of supportive subjects and supplementary subjects (Ministry of Education, 2010). Students can choose from four fields of study: social sciences, natural sciences, commerce, or technology. Mathematics is one of the core subject under natural science.

Namibian high school mathematics curriculum aims to prepare students to use mathematics effectively in their personal and professional lives (Ministry of Education, 2009a, 2009b). Students have to pass their mathematics courses until the $10^{\text {th }}$ grade. They can continue with their further education even if they fail the $10^{\text {th }}$ grade mathematics. Yet, when they start the $11^{\text {th }}$ grade, they are expected to have problem solving skills and knowledge of number systems, algebraic equations, exponents, trigonometry, a wide range of geometry concepts, and basic statistics for their further learning of mathematics. Namibian mathematics curriculum for high school is a two-year program targeting grades 11 and 12 for both ordinary and higher levels including the following topics: numbers and operations, measurement, geometry, algebra, graph and functions, coordinates geometry, trigonometry, vectors and transformations, and statistics and probability (Ministry of Education, 2009a, 2009b). There is no official guide or document that specifies which topics should be covered in grade 11 and grade 12. Regions or schools consequently decide which topics to teach in grade 11 when designing the scheme of work. It is generally the case that most of the topics are taught in grade 11 so that teachers and students have sufficient time to revisit the course materials in preparation for the national examination at the end of grade 12. Therefore, grade 11 is important in the Namibian education system as most of the mathematics content in the curriculum is taught at this grade level.

There are two mathematics tracks at the high school level as ordinary level (core or extended) or higher level. The core level is easier and it aims to ensure that students are able to use numbers with understanding as well as basic ideas about some more advanced topics such as trigonometry, geometry (including topics such as constructions and angle properties), statistics and probability, functions, and algebra (Ministry of Education, 2009a). Extended level mathematics has more complex mathematics concepts such as coordinate geometry, logarithms, and polynomials (Ministry of Education, 2009b), whereas higher level mathematics has advanced concepts such as exponential functions, statistics, probability, vectors, sequences, differentiation and integration (Ministry of Education, 2009b). The highest course grade is seven at the ordinary level and nine at the higher level.

\section{Namibian teacher education program}

Namibia has only one general public university with six campuses located in different regions that are also responsible for teacher education. In addition, six private universities train teachers in the country. Entering a mathematics teacher education program requires (i) a total of 25 points on the Namibian university evaluation scale gathered from five courses with the highest grades at the high school and (ii) higher level of achievement in mathematics and English in grade 12.

Namibian secondary mathematics teacher education is a four-year bachelor's degree program focusing on connecting the content knowledge and pedagogical knowledge. Preservice teachers, who will be specialized in high school mathematics education (grades 11-12), are trained on the content knowledge and pedagogy with optional physics or biology supplemental subjects. Preservice teachers have teaching practice in three phases in the $2^{\text {nd }}, 3^{\text {rd }}$, and $4^{\text {th }}$ year of the program where they work as student teachers in the $11^{\text {th }}$ and $12^{\text {th }}$ grade mathematics lessons by increasing their teaching time in each phase.

The mathematics teacher education program addresses a range of mathematics teaching methods because preservice teachers will meet students with different mathematics learning needs. The courses cover effective uses of different teaching methods, such as demonstration, experimentation, lectures, group work and discovery methods. Effective use of technology in mathematics teaching and learning is also promoted in the courses. Preservice teachers are introduced theoretical and practical aspects of the teaching profession in the university courses and their teaching practices are observed and assessed in their practicums by the teacher educators and the teachers in the practicum schools.

\section{Participants and Data Collection}

Four preservice teachers in their last semester in the teacher education program and three teacher educators in the same program were the participants of the study. Data were collected from all participants in both parts of the study via semi-structured interviews. Part I was conducted during October 2018 shortly before preservice teachers graduated from the teacher education program. Preservice teachers graduated from the university in November 2018 and started to work at schools as teachers in the following school year. Part II data were collected in July 2019. School year in Namibia starts in January and ends in November.

The purpose of the semi-structured interviews were to gather data from participants about their beliefs about MLD by encouraging them to reflect upon their related experiences and observations especially at the high school level because these experiences and observations lead to their beliefs (Pajares, 1992; Philipp, 2007). Interviews were audio-recorded based on participants' consent and transcribed verbatim. All interviews were conducted by the researcher in a silent and private place that participants preferred and took 30 to 60 minutes. 
Table 1. Examples of Common Interview Questions in Part I with their Aims and the Literature Connection

\begin{tabular}{|c|c|}
\hline Interview Questions & Aim and the Literature Connection \\
\hline $\begin{array}{l}\text { What are the factors that contribute to MLD among high } \\
\text { school students, especially the 11th grade? }\end{array}$ & \multirow{2}{*}{$\begin{array}{l}\text { To explore participants' beliefs about the reasons of MLD, such as whether they } \\
\text { address out-of-school factors or school related factors (or both) for students with } \\
\text { MLD (based on Beswick, 2007/2008; Georgiou, 2008; Maemeko, Nkengbeza, \& Ntabi, } \\
\text { 2017; Nambira et al., 2009; Soodak \& Podel, 1994). }\end{array}$} \\
\hline Why do you think students fail mathematics? & \\
\hline $\begin{array}{l}\text { What teaching strategies would be useful in teaching } \\
\text { students with MLD? }\end{array}$ & $\begin{array}{l}\text { To explore participants' beliefs about effective practices to teach students with MLD } \\
\text { (based on Zohar et al., 2001). }\end{array}$ \\
\hline How can we support students with MLD? & $\begin{array}{l}\text { To explore participants' beliefs about the type of interventions (out-of-school or } \\
\text { school-related) that could be effective in supporting students with MLD (based on } \\
\text { Soodak \& Podell, 1994). }\end{array}$ \\
\hline
\end{tabular}

\section{Part I (2018)}

Four senior preservice high school mathematics teachers and three mathematics teacher educators from the Department of Mathematics, Science, Sport and Education in one of the Namibian general public university campuses volunteered for the study. The teacher education program was selected based on convenience to the researcher. Although the head of the department at the university campus assisted in announcing the study to the senior preservice high school mathematics teachers in their final year of the teacher education program, participant recruitment was not easy due to the busy schedule and workload of the preservice teachers. The preservice teachers who were available and willing to participate in the study became the participants. The researcher tried to ensure the gender balance in accessing participants.

The selected public university department had 100 preservice teachers trained to teach mathematics at the high school level and 28 of them were in their last year in the program. Participating preservice mathematics teachers (two males and two females, ages 22-26) were at the last year of their teacher education studies. They had completed several mathematics education courses related to assessment, educational research, teaching methods, and more, and were close to completing their studies.

The three teacher educators (one male and two females), on the other hand, were the only available mathematics educators in the department at the time of the data collection and they all volunteered for this study. Teacher educators had more than 15 years of previous experience in teaching high school mathematics and were working at the university during the interviews. Two of them had more than ten years of experience in teaching to the preservice teachers and one had less than five years of teaching experience. One teacher educator had a Bachelor Degree of Honours in mathematics as the highest qualification and the other two had doctoral degrees in mathematics education as their highest qualification. Teacher educators were responsible for teaching mathematics and mathematics education courses in the program and guiding and monitoring preservice teachers in their practicum at schools.

The interview protocol for the preservice teachers and teacher educators were designed based on the literature review about teachers' beliefs about MLD and learning difficulties, and the belief definition adopted for the study. The protocols were revised by researchers in the field. Participants were encouraged to reflect on their experiences in and observations of classrooms about the students with MLD with six common major questions and some follow up questions asking participants to elaborate or give examples. Illustrative common questions and their aim and connection to the literature are given in Table 1.

The interview protocol was the same for both preservice teachers and teacher educators except one question about preparedness to teach students with MLD. The preservice teachers were asked how prepared they were as they were close to completing the teacher education program, whereas the teacher educators were asked to share their perspectives on how ready the preservice teachers were at the end of the program to meet the needs of students with MLD. These questions also produced belief statements especially about supporting students with MLD.

Part I interviews focused on MLD especially in the beginning of the high school ( $11^{\text {th }}$ grade) and how teachers could support students with MLD. The 2018 interviews provided insight into preservice teachers' beliefs, and what kind of views and practices might be emphasized by teacher educators about MLD in the teacher education programs.

\section{Part II (2019)}

In 2019, the four preservice teacher participants graduated from the program, were appointed as teachers at the state schools in three different Namibian regions and volunteered to participate in Part II. Participants were interviewed at the second semester of their first year of teaching. Three of them were teaching at rural schools and one at a semi-urban school. All of them were teaching primary or junior primary grades because they could not find teaching opportunities at high schools. Only one of them was teaching also at the high school and specifically at the $11^{\text {th }}$ grade. All four participants stated that they taught about 40 lessonhours each week, including mathematics lessons and other school subjects allocated to them.

Interview protocol in Part II aimed to elicit teachers' (former preservice teachers) beliefs about MLD based on their experiences and observations in their first year as a teacher. Part II interview protocol had eight main questions and follow up questions asking for elaboration and examples. There were changes in the interview questions due to the employment of participants in different levels of schooling. Illustrative questions and their aim and connection to the literature are given in Table 2. 
Table 2. Examples of Interview Questions in Part II with their Aims and the Literature Connection

\begin{tabular}{|c|c|}
\hline Interview Questions & Aim and the Literature Connection \\
\hline How do you define MLD? & $\begin{array}{l}\text { To explore participants' beliefs about MLD with follow up questions on their } \\
\text { observations and experiences based on the responses. }\end{array}$ \\
\hline How do you understand that a student has MLD? & \multirow{2}{*}{$\begin{array}{l}\text { To explore participants' beliefs about MLD and indicators of MLD, with follow up } \\
\text { questions on their observations and experiences based on the responses (based } \\
\text { on Beswick, 2007/2008; Georgiou, 2008; Maemeko et al., 2017; Nambira et al., } \\
\text { 2009; Soodak \& Podel, 1994). }\end{array}$} \\
\hline $\begin{array}{l}\text { What are the things that they can do in the mathematics } \\
\text { classroom? What are the things that they cannot do? }\end{array}$ & \\
\hline $\begin{array}{l}\text { What are the influences of national curriculum to your } \\
\text { teaching profession in relation to teaching students with MLD? }\end{array}$ & $\begin{array}{l}\text { To explore teachers' beliefs about the systemic factors that affect their } \\
\text { practices in relation to students with MLD (based on Haser \& Star, 2009). }\end{array}$ \\
\hline
\end{tabular}

Part II questions focused on how participants identified MLD and how they addressed students with MLD in the classroom. We anticipated that certain factors, which they might have observed but did not experience as a student teacher in 2018 , such as the national curriculum, might be affecting their teaching, and asked specific questions about them.

\section{Data Analysis}

The data of the study were the verbatim transcriptions of the audio-recorded interviews with the participants. Beliefs about MLD have not been widely investigated in the mathematics education field, especially in Namibia. Therefore, open coding procedure was employed to allow us to see all possible understandings that participants expressed in relation to their observations and experiences within the data set (Corbin \& Strauss, 2008), and eventually to their beliefs (Philipp, 2007). Open coding also allowed us to explore possible connections among participants' beliefs within their belief systems.

First, the researcher read the data several times to familiarize herself with the participants' experiences. She took notes on commonalities of meanings and understandings within the data among all participants, and separately among preservice teachers and teacher educators. These notes on the meanings and understandings led to a possible list of codes that could be used in analyzing the data (Corbin \& Strauss, 2008). After the researcher analyzed the data with these initial codes and gathered initial findings, both authors discussed about the initial findings and possible further codes. This was followed by a second coding done by the researcher with a refined code list and a joint discussion where both authors agreed on overarching themes grounded in the data that answered the research questions. A list of quotations from the participants were gathered for each theme and revised by the second author, which ensured the accuracy of the coding process.

\section{Trustworthiness}

Several strategies suggested by Creswell and Poth (2018) were employed in order to establish the trustworthiness of the study. The researcher's (the first author) engagement in the Namibian education system and her close monitoring of the teacher education in Namibia ensured prolonged engagement in the context and provided the data collection and analysis processes with an undivided focus on the research questions. Meanwhile, the second author, who has not been involved in Namibian education system, acted as a peer reviewer, monitored the coding process of the data closely and asked critical questions in order to reach a working coding list and the most possible accurate coding, as well as an accurate report of the research. This monitoring process also led to several discussions between the second author and the researcher targeting possible researcher bias of the researcher and encouraged her to reflect on her experiences and judgements. The detailed description of the Namibian education system, secondary education, and the teacher education provided readers a base to determine to what extend the findings could be relevant to their educational contexts. In brief, the careful and closely monitored coding process, continuous critical discussion among the authors, the different involvement of the authors with the context, and the detailed descriptions of the context have increased the trustworthiness of the study.

\section{FINDINGS}

\section{Preservice Teachers' and Teacher Educators' Beliefs (Part I)}

Both preservice teachers and teacher educators stated beliefs about MLD in relation to students' knowledge and beliefs. Teacher educators expressed beliefs about teachers' knowledge, beliefs and practices in relation to MLD. Preservice teachers stated that curriculum and teachers' workload affected MLD. Both groups of participants suggested approaches to support students with MLD especially at the beginning of the high school.

\section{Students' knowledge and beliefs}

All participants addressed the importance of students' knowledge and beliefs as a factor affecting MLD. Preservice teachers believed that students needed a strong mathematics knowledge base that should be built at the earlier grades. When students lacked a strong knowledge base, they were very likely to have MLD at the upper grades: "At lower grades sometimes they [students] don't really get that strong mathematics foundation. It is hard to catch-up when you are at upper grades." Teacher educators also believed that students have MLD because of insufficient background knowledge in the subject and addressed students' knowledge base as a crucial factor for learning of new concepts. On the other hand, for a student "with the good foundation, [mathematics] will not be a problem" at the high school as stated by one of the teacher educators.

Preservice teachers stated that some students believed "mathematics is harder, I do not think I can do this" regardless of teachers' efforts. They said that such beliefs would negatively affect students' behaviors toward the teacher or mathematics, and 
they would fail eventually. Similarly, teacher educators stated that if students came to the mathematics lesson with the belief that it would be difficult, then they would not bother to concentrate because they would believe that they were "not good at mathematics." Students might start the school with the belief that "My mom was also at school [and cannot do mathematics] and dad is still struggling, how can I do it?" and would not believe that they could be successful in mathematics. All participants agreed that students with such beliefs would not enjoy learning mathematics, would not be motivated to learn mathematics and in turn, would have MLD.

Preservice teachers stated that students might have different reasons (such as lack of commitment, background knowledge or productive dispositions) for having MLD in one topic but not the other: "It is not that they have difficulties in all areas, they probably [have difficulty] just in a specific area where they do not understand." However, they observed that students with MLD rarely would raise their hands when they could not understand because they would have a "fear of asking [questions to the] teachers." Teacher educators added that "learners are too scared of making mistakes" and this would make them miss the learning opportunities from their mistakes. Lack of practice was also a reason in addition to not asking questions. Preservice teachers believed that "in mathematics we need more practice" of what was taught and students would have MLD because "sometimes they do not like to practice."

Interestingly, teacher educators mentioned students' new learning environment in relation to MLD. They stated that the majority of the $11^{\text {th }}$ graders come from comprehensive schools where they attended all grades from 1 to 10 , and they were in smaller class-groups and familiar with their teachers, unlike the high schools. The $11^{\text {th }}$ graders "are still getting acquainted with the culture of the [new] school. They are not used to the teacher. They are trying to adopt." It "is already toward the end of grade 11" when they become familiar with the teacher, and "they don't really perform at their highest potential" and would have difficulties in learning mathematics.

\section{Teachers' knowledge, beliefs and practices (as observed)}

Preservice teachers did not comment on teachers' knowledge and practice in relation to MLD as teacher educators did. Teacher educators indicated that some teachers did not have sufficient mathematics knowledge and effective teaching strategies for teaching mathematics. One teacher educator expressed that primary teachers were sometimes assigned to teach higher grades because of lack of staff. However, these teachers were "not competent" to teach mathematics concepts effectively at that level, which resulted in lack of essential mathematics knowledge base for high school students. Some teachers "believe the only way to teach the students mathematics is to teach them how to follow the procedures" and they would not explain to students why the procedures worked. Teacher educators believed that these practices might negatively affect students' learning, as they would still lack essential knowledge base especially if strategies to solve mathematical problems were not well explained, and might further lead to MLD. They believed that teachers "should teach students how to follow procedures [... but they] should teach them with understanding. For them to be able to know what they are doing and why they are doing it."

Teacher educators pointed that teachers' lack of competency could be traced back to their earlier education. They stated that some of the first-year student teachers were not equipped to take mathematics at the university level as "they lack[ed] the background." For those who had done core level (the lowest level), "they ha[d] no clue on what is going on" about the concepts covered in the first year of the program, which they believed might result in ineffective teaching in the future. However, student teachers who studied mathematics at the higher or extended level were "hardly even to struggle."

\section{Curriculum and teachers' workload}

Preservice teachers observed that teachers did not have time to provide extra learning support to the students who had MLD because of the heavy workload: "[B]ecause of overloaded curriculum, the syllabus itself [...] mostly, they don't have that time of adding extra burden [...] to make sure their learners are equipped." The mathematics content at the high schools was too broad, difficult and "more advanced." They observed that teachers had several classes at different grades to teach, which made it difficult for them to assist students during the lesson and after the school day. Interestingly, teacher educators did not comment on these issues in relation to students' MLD.

\section{Supporting students with MLD}

All participants believed that teachers, students, and schools were responsible for supporting students with MLD. Preservice teachers believed that students with MLD could only perform well if they concentrated, participated, and put effort in their studies. They observed that students would not always understand teachers' explanations, which could be a barrier in their learning and might further influence their attitudes towards mathematics. Preservice teachers believed that teachers needed to arrange extra support in groups or in pairs and "re-teach a topic" to those who did not fully understand the topics. They indicated that they would spend effort to understand the differences among their future students and would try to support their learning in certain ways, such as "instead of attending to them one by one, [they] will attend to them as a group." At the same time, they would try to provide help for individual students on a one-to-one basis while others would be completing the group work. They would be "using different teaching strategies," and giving them many activities. They stated that this would also help in developing good relationship with their students, and might arouse students' interest in mathematics. Preservice teachers believed that students should practice as much as possible and interact with other students while solving problems in order to overcome MLD.

Teacher educators believed that students learned at different paces, as some would understand fast and might be bored in the lesson. However, for students with MLD, "it does not mean that they cannot do mathematics, but they still need time" and learning support. Therefore, first, teachers should identify students who had MLD and to provide those students with the necessary support. They believed that one-on-one teaching would aid students in their understanding, and suggested that teachers should integrate teaching strategies for several learning styles and allow students to choose what would make sense the 
most. Teacher educators believed that teachers needed to find strategies that would make students love and understand mathematics because, "you cannot pass something that you don't understand." Thus, teachers also needed to understand why their students had MLD.

Students should also be willing to commit themselves and remove "negative connotations" they might have created related to the difficulty of a subject. One preservice teacher narrated, "if you have a belief that mathematics is difficult, you will fail the subject." They believed that students should enjoy learning mathematics, because if students were enjoying mathematics they "will want more and more, until [they] come to a point of understanding."

Teacher educators and preservice teachers believed that schools should have a timetable where a specific teacher would have a regular time in the afternoon to give extra support to students with MLD and teachers should be willing to give support to them. Teacher educators emphasized that extra support would stimulate students' interest towards the subject. Further, they stated that students should understand the importance of such a program and how it would influence their performance.

\section{Teachers' Beliefs in their First Year (Part II)}

Preservice teacher participants of Part I became teachers in 2019 and volunteered to participate in Part II of the study. They were referred as "teachers" in Part II findings. Findings below do not address teachers' beliefs about MLD specifically at the high school grades, but also at lower grade levels because participants worked at different grade levels. The analysis revealed beliefs similar to those they addressed in Part I, but with more elaboration this time and emphasis on their practices as teachers, as documented below.

\section{Students' knowledge, beliefs and dispositions}

Teachers expressed more details on students with MLD in their first-year teaching. They believed that the lack of essential prerequisite knowledge was the basis of MLD. Students with MLD lacked "understanding of effective and useful strategies to solve mathematical problems," and they "demonstrate[d] slow or inaccurate recall of basic arithmetic facts" especially in the lower grades. The teacher who taught at the $11^{\text {th }}$ grade also observed that some students could not even identify or tell "a variable or which one is a coefficient or index." One teacher stated that students with MLD "have difficulties in representing mathematical concepts mentally."

Teachers stated that certain attitudes and beliefs also seemed to be the reasons of MLD. They believed that students' lack of interest in learning mathematics resulted in not following the classroom activities in the mathematics lesson. Such students "[would] not participate in class [... would] not practice and ask for assistance, and they [would] not get discouraged by failing." Some of the students with MLD wanted to understand the mathematics concepts, but they believed that mathematics was difficult for them. These students did not think of asking questions about a mathematics concept they did not fully understand in the lesson and continued to have more difficulties in further topics. Teachers tried to guide these students by explaining that mathematics was not difficult and by encouraging them to do a series of mathematics activities for practice because they believed that "what matters in mathematics is practice" and "once [students] practice more, [they would not] find it difficult."

\section{Teachers' (own) practices}

Teachers elaborated on their own practices in the classroom in relation to MLD in 2019. They realized that their practices did not always effectively address all students and especially those with MLD. Teachers stated that classrooms might have different types of learners who did not make sense of mathematical concepts in the same way and certain approaches might not work for some students. Giving learners a fundamental piece of information about a certain topic in mathematics and expecting them to build sound mathematical thinking and reasoning on their own "does not always yield desirable results. It might work for a certain group of learners in class A but it can be a total failure in class B."

Teachers sometimes tried other approaches which might not be as effective as they expected. They stated that if they identified a learner with MLD, then they placed him/her in a group of others who did not have MLD to support his/her learning. However, this strategy did not always work for all students and "that learner [would] not even pay attention to others. [Students with MLD] lose concentration and lose interest in mathematics as a subject." Teachers voiced that such students failed tests and examinations. When teachers called these students to give extra learning support, "only some show up [...] and you can tell [the student] is not concentrating."

Participants had difficulties in addressing the students with MLD when they became teachers. While they did not still mention about the consequences of their mathematical knowledge in terms of students' MLD, they reflected more on their practices to address MLD in the classroom. Their experiences in the classrooms and observations of students indicated that they seemed to be in the process of developing beliefs that not all students with MLD would benefit from the same practice in the same way.

\section{Curriculum and teachers' workload}

Teachers identified more issues about curriculum and workload in relation to MLD as they had first-hand experience at schools. All teachers believed that mathematics content in all grades of lower secondary school accommodated all students, with or without MLD. However, the teacher who also taught at the $11^{\text {th }}$ grade addressed that the mathematics content at the high school level was excessive and it did not support students with MLD.

The curriculum, however, created considerable workload for all teachers. They stated that the workload was too much, and they would not be able to "finish the syllabus on time." This situation led some teachers not to spend extra effort for students with $M L D$, as there was not enough time to give learning support to them during the lessons: 
"I don't attend to them fully to make sure they understood or they are at the same level as the others, because I am too overloaded. The guidelines given in the national curriculum documents how to address learners with MLD are time consuming and not effective. If we are to apply them, we cannot finish the syllabus on time."

Student enrolment in classrooms was another factor to the teachers' workload. Teachers generally had populated classrooms (over 40 students) and "giving each and every learner one by one an opportunity to explain mathematical reasoning is not possible in 40 minutes because the syllabus needs to be covered in preparation for the end of term examinations." Teachers stated that crowded classrooms made it difficult to give activities or assistance to every individual student and this might bring disadvantage to those with MLD.

One teacher addressed that MLD might result from employing English as a medium of teaching because some students did not understand either the explanations or what the question was asking, which caused MLD for these students. This teacher tried to deal with it by explaining the same concept several times by using the students' local language.

\section{Supporting students with MLD}

Teachers believed that identifying students with MLD and combining them in mixed ability groups or pairs would enable them learn better explanations from peers, despite some discouraging attempts. They further expressed that a series of mathematics activities were needed for students to work on during group or pair work with effective feedback. Interestingly, all teachers stated that they made themselves available during students' study time (after school hours) to do remedial teaching for students with MLD although this was a challenge to participants due to overloaded teaching responsibilities and large class sizes in some schools: "[...] even after school then you stay with the kid, even for 30 minutes to give extra classes. I think it can help learners to improve." One of the teachers believed that students with MLD also needed "more tasks to do, because [...] what matters in mathematics is practice. If you do not practice mathematics, you cannot make it seriously."

Two of the teachers further voiced about working with other colleagues in the mathematics department in their schools to coplan and co-teach once they had difficulty especially in explaining a certain mathematics concepts to students. Teacher believed that these efforts would help improving learning of students with MLD.

Teachers mentioned about some of the implementations at their schools that they believed effective in supporting students with MLD. Two of them stated that once a student was identified having MLD, their parents were invited to the school to determine a support strategy for the student where mostly, parents responded positively. One teacher stated that students with MLD were referred to the "learning support committee" of mathematics and language teachers in the school. The committee arranged a day to meet with the identified students and tried to see students' performance in given activities. The main goal of the committee was to see if the difficulty of the student was related to the language skills or mathematics skills. After the activities, the student would be asked to express him/herself on what difficulties he/she faced in learning mathematics. The teacher believed that this gave students the opportunity to consider and ask questions where they did not understand.

\section{DISCUSSIONS AND CONCLUSIONS}

The findings of the study showed that preservice teachers and teacher educators had similar observations about students with MLD and how it might have started and/or strengthened especially at the high school contexts to some extent. They believed that students' lack of previous knowledge, poor study habits, and beliefs about the difficulty of mathematics were among the major reasons of having MLD when they started high school. Preservice teachers believed that the density of the high school curriculum and teachers' workload seemed to make it difficult to attend to the students with MLD in the classrooms. Namibian teachers have identified similar reasons for students' low achievement in the previous studies (Maemeko et al., 2017; Nambira et al., 2009). Neither preservice teachers nor teacher educators attributed MLD to any disability or other out-of-school factors in this study. They did not indicate any beliefs that some students cannot learn and should not study mathematics. They stated that teachers and students were responsible for overcoming MLD and schools should provide extra support for students with MLD. Participants believed that MLD were a result of lack of learning opportunities and support, and were connected to personal (students' beliefs and attitudes), school (former unqualified teachers), and systemic (curriculum and teachers' teaching responsibilities) factors similar to what teachers have identified in previous studies (Maemeko et al., 2017).

Participants' and especially preservice teachers' beliefs could be considered as a positive aspect for effective professional development programs to support teachers' practices for students with MLD. Yet, such beliefs might also lead teachers towards ignoring out-of-school factors (such as study environment at home and parental support) which might reinforce an existing MLD or reduce the effects of school-based efforts for students with MLD. Although understanding the school-based reasons and developing instructional supports for students with MLD are important for successful attempts to address students with MLD (Beswick, 2007/2008), it is crucial that teacher educators emphasize possible out-of-school factors in the programs so that preservice teachers consider them when they organize and maximize their efforts for students with MLD.

Preservice teachers' and teacher educators' beliefs about MLD were aligned to some extent, which might indicate that preservice teachers developed beliefs about MLD that were somehow in line with the emphasized ideas and practices in the teacher education program (Felbrich et al., 2008). However, preservice teachers did not mention about the effects of teachers' knowledge and practices on MLD, and the difficulty of beginning to study at a different school environment for the high school students in relation to MLD. They addressed the negative consequences of students' existing insufficient knowledge in terms of MLD. They observed the influence of previous teachers on students' MLD in these grade levels, but did not reflect on how their knowledge and practices might influence students with MLD or might cause MLD for some students who did not have it before. On 
the other hand, teacher educators did not state any causes of MLD related to curriculum or teachers' workload. It might be the case that, preservice teachers spent more time with the teachers, observed them in-and-out of the classroom and focused on their struggles more. They might not be in a position to evaluate high school mathematics teachers' knowledge and skills in relation to MLD because they were in the process of learning to become one. However, teacher educators might have observed teachers only during specific lessons and might not see their struggles in their out-of-class work. These differences addressed that preservice teachers might not be aware of how their knowledge (of mathematics, mathematics teaching, and students) and practices would affect students with MLD, and therefore, might not reflect on these. The lack of reflection might hinder (preservice) teachers from identifying MLD-related knowledge and practices they need to improve, and looking for opportunities for improvement. On the other hand, teacher educators mentioned only individual support while preservice teachers also addressed pair/group work to support students with MLD. Preservice teachers might have observed group work at schools, not necessarily in relation to MLD, and devised further plans for students with MLD including group work.

There were several challenges that preservice teacher participants had to deal with when they became teachers. These challenges seemed to make them elaborate more on students with MLD, this time at different grade levels, with more insight about their own practices and students with MLD. They experienced the teaching conditions as teachers and realized certain difficulties, such as teaching in crowded classrooms in the national curriculum context and the possible consequences for students with MLD, and realized that their strategies to deal with MLD might not work for all students. Such challenges that beginning teachers face in their first years in the national curriculum contexts might have consequences, such as change in beliefs and/or practices, as they try to deal with them and ensure students' learning simultaneously (Haser \& Star, 2009). Yet, teachers' beliefs about MLD did not seem to change much in their first year except that they expressed the need for diverse approaches to address students' MLD. They stressed group work for students with MLD despite some failed attempts, but they also seemed to realize that they needed to plan specific tasks for the groups. Although they addressed the importance of understanding the nature of MLD for each of their students who had it, they did not seem to consider the individual differences while planning their teaching. This shows that teacher education programs should emphasize multiple approaches to deal with different MLD in the classrooms especially in the context of the curriculum with emphasis on planning flexible tasks based on students' MLD.

Preservice teacher participants also observed measures taken in their schools to address MLD and collaborated with their colleagues for students with MLD when they became teachers. These observations and experiences could support beginning teachers' practices for students with MLD in their current and future teaching. Schools might benefit from engaging beginning teachers in their efforts to deal with students' MLD so that they would learn more about these efforts and enhance their related practices.

Preservice teacher participants emphasized the importance of "practice" in relation to MLD in both Part I and II. Although the study did not have a sufficient data set on participants' mathematics related beliefs, the emphasis on "practice" raises questions about how their beliefs about MLD might be related to their beliefs about the nature of mathematical knowledge, and about teaching and learning mathematics. Teachers (preservice participants) were asked about what students with MLD could or could not do in the mathematics classroom. We expected that participants would express both procedural and conceptual difficulties as indicators of MLD. However, they only addressed procedural difficulties, such as lack of arithmetic skills and recalling arithmetic facts, and poor number skills, but did not state much about the conceptual difficulties, such as lack of building connections among mathematics concepts or of conceptual knowledge. Combined with their emphasis on the "practice", we cautiously speculate that their beliefs about MLD might be derivatives of their beliefs about what is important to know and how to learn it in mathematics (in order not to have MLD) in their belief systems.

Why participants did not indicate the lack of conceptual difficulties as an indicator of MLD might also be related to their beliefs about what knowledge and skills characterized a student with MLD and one without MLD. Although they did not explicitly state, they might believe that only knowing certain mathematical knowledge and being able perform certain procedures would be sufficient for a student with MLD in order not to have any difficulties and manage school mathematics. As the literature reports similar explicit findings (Beswick, 2007/2008; Zohar et al., 2001) and interpretations (Beswick, 2017), we suggest that teachers' beliefs about MLD should be explored in relation to their beliefs about students without MLD and/or with high performance in mathematics in their belief systems. We further argue with caution that preservice teachers might be holding rather non-evidential beliefs about MLD, but they might develop more evidentially-held beliefs about MLD during their first year teaching in their belief systems as they taught students with MLD. Their beliefs about what students with MLD should be able to do and what kinds of knowledge and skills should be expected from them might be strengthened, and be evidentially held. Yet, we remind that our data set was limited to make strong arguments about participants' mathematics related belief systems.

When participants started to teach in Part II, all of them taught at lower grade levels and only one of them also taught at the high school level. Yet, all teachers had similar beliefs about MLD regardless of the grade levels they taught except for their beliefs about the curriculum. The participant who taught at the high school level believed that the content in the high school curriculum was not supporting the students with MLD, while they all believed that the curriculum at the lower grade levels were appropriate for students with and without MLD. Yet, all participants believed that the workload that the curriculum brought was excessive for the teachers. Preservice teachers' curriculum-related difficulties when they became teachers suggested that there was a lack of discussion of curriculum in relation to the students with MLD in teacher education programs. This, in turn, might have contributed to teachers' heavy workload of maintaining a curriculum pace and attending to the needs of students with MLD simultaneously. Their beliefs might not differ based on the grade level they taught because the circumstances and the experiences were mostly similar for all teacher participants.

It should be emphasized that Namibian preservice teachers and teacher educators characterized students with MLD also in terms of beliefs and attitudes in similar ways documented before (Beswick, 2017). While such findings are scarce in the literature, 
they might show that teachers are careful about students' beliefs and attitudes, and they believe that these constructs were important in dealing with MLD in the classrooms.

The findings point out that teacher education programs should provide preservice teachers with opportunities to reflect on their knowledge, beliefs and practices, and the possible consequences of their lack of essential mathematics and pedagogical knowledge in relation to MLD. In connection to this knowledge, preservice teachers' beliefs on what kinds of mathematics knowledge and skills that all students, including students with MLD, should have must be continuously discussed in the teacher education programs. National curriculum contexts can be overwhelming especially for beginning teachers when they try to cover all objectives for all students with or without all the prerequisite knowledge (Haser, 2010). The findings illustrate that it is difficult for beginning teachers to implement the curriculum in a classroom including students with and without MLD, especially when the class size is large. Therefore, both teacher education and national policies should consider such challenges when preparing teachers and designing the curriculum.

It should be noted that our findings were limited by the responses to the interview questions given by four preservice teachers and three teacher educators from Namibia. We did not observe teacher education courses and participants' teaching. We also did not explore the beliefs and practices of teachers who were observed by the preservice participants. Yet, the findings provide insight into a rarely researched topic and country in mathematics education. Further studies should address both the topic and the context more thoroughly.

\section{ACKNOWLEDGEMENTS}

This research was supported by Namibia Commission for Research Science and Technology in collaboration with University of Turku Graduate School.

\section{REFERENCES}

Beswick, K. (2007/2008). Influencing teachers' beliefs about teaching mathematics for numeracy to students with mathematics learning difficulties. Mathematics Teacher Education and Development, 9, 3-20.

Beswick, K. (2017). Raising attainment: What might we learn from teachers' beliefs about their best and worst mathematics students? In C. Andra, D. Brunetto, E. Levenson, \& P. Liljedahl (Eds.) Teaching and learning in mathematics classrooms (pp. 95106). Switzerland: Springer International Publishing. https://doi.org/10.1007/978-3-319-49232-2_10

Beswick, K. (2018). Systems perspectives on mathematics teachers' beliefs: Illustrations from beliefs about students. In E. Bergqvist, M. Österholm, C. Granberg, \& L. Sumpter (Eds.), Proceedings of the 42nd conference of the international group for the psychology of mathematics education (v.1, pp. 3-18). Umeå, Sweden: PME.

Carnine, D., Jitendra, A. K., \& Silbert, J. (1997). A descriptive analysis of mathematics curricular materials from a pedagogical perspective: A case study of fractions. Remedial and Special Education, 18(2), 66-81. https://doi.org/10.1177/074193259701800201

Chinn, S. (2015). An overview. In S. Chinn (Ed.) The Routledge international handbook of dyscalculia and mathematical learning difficulties (pp. 1-17). London; New York: Routledge. https://doi.org/10.4324/9781315740713

Corbin, J., \& Strauss, A. (2008). Basics of qualitative research: Techniques and procedures for developing grounded theory (3rd ed.). Thousand Oaks, CA: Sage. https://doi.org/10.4135/9781452230153

Creswell, J. W., \& Poth, C. N. (2018). Qualitative inquiry and research design: Choosing among five approaches (4th ed.). Thousand Oaks, CA: Sage.

Cross Francis, D., Rapacki, L., \& Eker, A. (2015). The individual, the context, and practice: A review of the research on teachers' beliefs related to mathematics. In H. Fives, \& M. Gregorie Gill (Eds.) International handbook of research on teachers' beliefs (pp. 336-352). New York, NY: Routledge.

DeSimone, J. R., \& Parmar, R. S. (2006a). Middle school mathematics teachers' beliefs about inclusion of students with learning disabilities. Learning Disabilities Research \& Practice, 21(2), 98-110. https://doi.org/10.1111/j.1540-5826.2006.00210.x

DeSimone, J. R., \& Parmar, R. S. (2006b). Issues and challenges for middle school mathematics teachers in inclusion classrooms. School Science and Mathematics, 106(8), 338-348. https://doi.org/10.1111/j.1949-8594.2006.tb17754.x

Donche, V., \& Van Petegem, P. (2011). Teacher educators' conceptions of learning to teach and related teaching strategies. Research Papers in Education, 26(2), 207-222. https://doi.org/10.1080/02671522.2011.561979

Felbrich, A., Müller, C., \& Blömeke, S. (2008). Epistemological beliefs concerning the nature of mathematics among teacher educators and teacher education students in mathematics. ZDM Mathematics Education, 40(5), 763-776. https://doi.org/10.1007/s11858-008-0153-5

Fives, H., \& Buehl, M. M. (2012). Spring cleaning for the "messy" construct of teachers' beliefs: What are they? Which have been examined? What can they tell us? In K. R. Harris, S. Graham, \& T. Urdan (Eds.) APA educational psychology handbook volume 2: Individual differences and cultural and contextual factors (pp. 471-499). Washington, DC: APA. https://doi.org/10.1037/13274019 
Flores, M. A., \& Day, C., 2006. Contexts which shape and reshape new teachers' identities: a multi perspective study. Teaching and Teacher Education, 22(2), 219-232. https://doi.org/10.1016/j.tate.2005.09.002

Furinghetti, F., \& Pehkonen, E. (2002). Rethinking characterizations of beliefs. In G. C. Leder, E. Pehkonen, \& G. Törner (Eds.), Beliefs: A hidden variable in mathematics education? (pp. 39-58). Dordrecht: Kluwer Academic Publishers. https://doi.org/10.1007/0306-47958-3_3

Georgiou, S. N. (2008). Beliefs of experienced and novice teachers about achievement. Educational Psychology, 28(2), 119-131. https://doi.org/10.1080/01443410701468716

Goldin, G., Rösken, B., \& Törner, G. (2009). Beliefs - no longer a hidden variable in mathematical teaching and learning process. In J. Maasz \& W. Schlöglmann (Eds.), Beliefs and attitudes in mathematics education: New Research Result (pp. 1-18). Rotterdam: Sense Publishers. https://doi.org/10.1163/9789087907235_002

Gomez, C. N., \& Conner, A. (2020). Impact of Cooney, Shealy, and Arvold's (1998) belief structures: A literature review and citation analysis. Journal for Research in Mathematics Education, 51(4), 468-503. https://doi.org/10.5951/jresematheduc-2020-0046

Green, T. F. (1971). The activities of teaching. New York: McGraw-Hill.

Haser, Ç. (2010). Learning to teach in the national curriculum context. European Journal of Teacher Education, 33, $289-302$. https://doi.org/10.1080/02619761003713894

Haser, Ç., \& Doğan, O. (2012). Preservice mathematics teachers' belief systems. Journal of Education for Teaching: International Research and Pedagogy, 38, 261-274. https://doi.org/10.1080/02607476.2012.668336

Haser, Ç., \& Star, J. R. (2009). Change in beliefs after first-year of teaching: The case of Turkish national curriculum context. International Journal of Educational Development, 29, 293-302. https://doi.org/10.1016/j.ijedudev.2008.08.007

Jordan, N. C., \& Levine, S. C. (2009). Socioeconomic variation, number competence and mathematics learning difficulties in young children. Developmental Disabilities Research Reviews, 15, 60-68. https://doi.org/10.1002/ddrr.46

Maaranen, K., Kynäslahti, H., Byman, R., Jyrhämä, R., \& Sintonen, S. (2019). Teacher education matters: Finnish teacher educators' concerns, beliefs, and values. European Journal of Teacher Education, 42(2), 211-227. https://doi.org/10.1080/02619768.2019.1566317

Maemeko, E. L., Nkengbeza, D., \& Ntabi, M. L (2017). Teachers' perceptions on the causes of poor academic performance of grade 12 learners in four selected schools in the Zambezi Region of Namibia. IJRDO-Journal of Educational Research, 2(4), 93-110.

Mazzocco, M. (2009). An introduction to the special issue: Pathways to mathematical learning difficulties and disabilities. Developmental Disabilities Research Reviews, 15(1), 1-3. https://doi.org/10.1002/ddrr.52

Merriam, S. B. (2009). Qualitative research: A guide to design and implementation. (3rd ed.). San Francisco, CA: Jossey-Bass.

Ministry of Education (2009a). Mathematics syllabus ordinary level grades 11-12. Okahandja, NIED. Retrieved from http://www.nied.edu.na

Ministry of Education (2009b). Mathematics syllabus higher level grades 11-12. Okahandja, NIED. Retrieved from http://www.nied.edu.na

Ministry of Education (2010). The national curriculum for basic education. Okahandja, NIED. Retrieved from http://www.nied.edu.na

Ministry of Education, Arts and Culture. (2017). The SACMEQ IV project in Namibia: A study of the conditions of schooling and the quality of primary education in Namibia. Retrieved from http://www.sacmeq.org/

Morgan, P. L., Farkas, G., \& Wu, Q. (2009). Five-year growth trajectories of kindergarten children with learning difficulties in mathematics. Journal of Learning Disabilities, 42(4), 306-321. https://doi.org/10.1177/0022219408331037

Nambira, G., Kapenda, L., Tjipueja G., \& Sichombe, B. (2009). Performance of learners in mathematics at upper primary phase in Okahandja District: Examining reasons for low performances. Research Unit, Division Professional Development and Research, NIED Okahandja. Retrieved from http://www.nied.edu.na/documents/research/

Pajares, M. F. (1992). Teachers' beliefs and educational research: Cleaning up a messy construct. Review of Educational Research, 62(3), 307-332. https://doi.org/10.3102/00346543062003307

Philipp, R. A. (2007). Mathematics teachers' beliefs and affect. In F. K. Lester (Ed.), Second handbook of research on mathematics teaching and learning (pp. 257-315). Reston, VA: National Council of Teachers of Mathematics.

Raymond, A. M. (1997). Inconsistency between a beginning elementary school teacher's mathematics beliefs and teaching practice. Journal for Research in Mathematics Education, 28(5), 550-577. https://doi.org/10.2307/749691

Reusser, K. (2000). Success and failure in school mathematics: Effects of instruction and school environment. European Child \& Adolescent Psychiatry, 9(2), 17-26. https://doi.org/10.1007/s007870070006

Richardson, V. (2003). Preservice teachers' beliefs. In J. Raths, \& A. C. McAninch (Eds.), Teacher beliefs and classroom performance: The impact of teacher education, volume 6: Advances in teacher education (pp. 1-22). Greenwich, CT: Information Age.

Scherer, P., Beswick, K., DeBlois, L., Healy, L., \& Opitz, E. M. (2016). Assistance of students with mathematical learning difficulties: How can research support practice? ZDM Mathematics Education, 48(5), 633-649. https://doi.org/10.1007/s1185 8-016-0800-1

Soodak, L. C., \& Podell, D. M. (1994). Teachers' thinking about difficult-to-teach students. The Journal of Educational Research, 88(1), 44-51. https://doi.org/10.1080/00220671.1994.9944833 
Southern and Eastern Africa Consortium for Monitoring Educational Quality (SACMEQ). (2011). Trends in achievement levels of grade 6 learners in Namibia. SACMEQ Policy Brief Number 1 (September 2011). Retrieved from www.sacmeq.org

Thompson, A. G. (1992). Teachers' beliefs and conceptions: A synthesis of the research. In D. A. Grouws (Ed.), Handbook of the research on mathematics teaching and learning (pp. 127-146). New York: Macmillan.

Van Steenbrugge, H., Valcke, M., \& Desoete, A. (2010). Mathematics learning difficulties in primary education: Teachers' professional knowledge and the use of commercially available learning packages. Educational Studies, 36(1), 59-71. https://doi.org/10.1080/03055690903148639

Warren, A. (2019). Modelling effective instruction in the teacher education classroom. (Doctoral Dissertation). Retrieved from https://rucore.libraries.rutgers.edu/rutgers-lib/60911/

Zohar, A., Degani, A., \& Vaaknin, E. (2001). Teachers' beliefs about low achieving student and higher order thinking. Teaching and Teacher Education, 17(4), 469-485. https://doi.org/10.1016/S0742-051X(01)00007-5 